\title{
Detection of deterministic and probabilistic convection initiation using Himawari-8 Advanced Himawari Imager data
}

\author{
Sanggyun Lee ${ }^{1}$, Hyangsun Han ${ }^{2}$, Jungho Im ${ }^{1}$, Eunna Jang ${ }^{1}$, and Myong-In Lee ${ }^{1}$ \\ ${ }^{1}$ School of Urban and Environmental Engineering, Ulsan National Institute of Science and Technology (UNIST), \\ Ulsan, 44949, South Korea \\ ${ }^{2}$ Unit of Arctic Sea-Ice prediction, Korea Polar Research Institute, Incheon, 21990, South Korea \\ Correspondence to: Jungho Im (ersgis@unist.ac.kr)
}

Received: 21 September 2016 - Discussion started: 1 November 2016

Revised: 19 March 2017 - Accepted: 24 April 2017 - Published: 24 May 2017

\begin{abstract}
The detection of convective initiation (CI) is very important because convective clouds bring heavy rainfall and thunderstorms that typically cause severe socio-economic damage. In this study, deterministic and probabilistic CI detection models based on decision trees (DT), random forest (RF), and logistic regression (LR) were developed using Himawari-8 Advanced Himawari Imager (AHI) data obtained from June to August 2016 over the Korean Peninsula. A total of 12 interest fields that contain brightness temperature, spectral differences of the brightness temperatures, and their time trends were used to develop CI detection models. While, in our study, the interest field of $11.2 \mu \mathrm{m} T_{\mathrm{b}}$ was considered the most crucial for detecting $\mathrm{CI}$ in the deterministic models and the probabilistic RF model, the trispectral difference, i.e. $(8.6-11.2 \mu \mathrm{m})-(11.2-12.4 \mu \mathrm{m})$, was determined to be the most important one in the LR model. The performance of the four models varied by CI case and validation data. Nonetheless, the DT model typically showed higher probability of detection (POD), while the RF model produced higher overall accuracy (OA) and critical success index (CSI) and lower false alarm rate (FAR) than the other models. The CI detection of the mean lead times by the four models were in the range of 20-40 min, which implies that convective clouds can be detected $30 \mathrm{~min}$ in advance, before precipitation intensity exceeds $35 \mathrm{dBZ}$ over the Korean Peninsula in summer using the Himawari-8 AHI data.
\end{abstract}

\section{Introduction}

Atmospheric deep moist convection initiates shallow cumulus clouds, which may continue to grow vertically as cumulonimbus clouds, and this process is called convective initiation (CI; Banacos et al., 2005; Bluestein et al., 1990; Weckwerth and Parsons, 2006). The moist convection appears in a variety of horizontal scales ranging from $1-10 \mathrm{~km}$ as individual convective clouds to $\sim 1000 \mathrm{~km}$ as mesoscale convective systems (Houze, 2004; Roberts and Lean, 2008; Miyamoto et al., 2013) with heavy rainfall and thunderstorm events (Amorati et al., 2000; Sieglaff et al., 2011; Zuidema, 2003; Haile et al., 2010; Hane et al., 2002; Vondou et al., 2010). The convective events in north-eastern Asia often occur during the summer season accompanied by many meteorological hazards such as lightning, floods, and strong winds (Kim and Lee, 2006; Wang et al., 2004). These hazards destroy infrastructure in the region and result in huge economic losses. Therefore, it is desirable to forecast CI in north-eastern Asia with high accuracy in order to prevent socioeconomic damage caused by the convective events.

The decrease of atmospheric stability drives CI, which is attributed to various weather systems such as large-scale monsoonal fronts, the migration of frontal cyclones, and mesoscale convective systems (Craven et al., 2002; Houze, 2004; Mecikalski and Bedka, 2006). Although such unstable weather systems can increase the potential risk of $\mathrm{CI}$ over a vast area, they actually trigger CI, occupying much smaller areas and making it difficult to predict the exact location. CI is characterized by the rapid variation of temperature and the increase of cloud tops, which can be effectively mea- 
sured by brightness temperature $\left(T_{\mathrm{b}}\right)$ changes at multispectral channels including visible and infrared (IR; Mecikalski and Bedka, 2006; Mecikalski et al., 2009, 2010). Geostationary satellites carry optical sensors that scan over a few thousand square kilometres with high temporal resolution $(\sim \min )$ in the multispectral channels. Therefore, these geostationary satellites can be extremely useful in CI nowcasting. Previous studies developed CI nowcasting algorithms for geostationary satellites by determining a threshold or a range of values of $T_{\mathrm{b}}$ at specific channels, and their spectral and/or temporal differences (Mecikalski and Bedka, 2006; Mecikalski et al., 2008; Walker et al., 2012; Morel and Senesi, 2002; Jewett and Mecikalski, 2013; Merk and Zinner, 2013; Siewert et al., 2010; Sobajima, 2012; Han et al., 2015). Geostationary Operational Environmental Satellite (GOES) systems and Meteorological Second Generation (MSG) are the representative geostationary satellites operated at the $\mathrm{Na}$ tional Oceanic and Atmospheric Administration (NOAA) and European Organization for the Exploitation of Meteorological Satellites (EUMETSAT), respectively. These two satellites have forecasted CI using their operational algorithms, i.e. SATellite Convection AnalySis and Tracking (SATCAST) and Rapidly Developing Thunderstorms (RDT) which are basically based on the empirical determination of the thresholds of interest fields in terms of CI development (Mecikalski and Bedka, 2006; Walker et al., 2012; Morel and Senesi, 2002). These algorithms have been assessed for CI cases in North America and showed a probability of detection (POD) over $0.8(80 \%)$ and a false alarm rate (FAR) around $0.6(60 \%)$. However, these algorithms for CI detection have not yet been validated over north-eastern Asia.

Several algorithms for detecting CI over north-eastern Asia have been developed by Korea Meteorological Administration (KMA) for the Multi-functional Transport SATellite-2 (MTSAT-2) geostationary satellite operated by Japan Meteorological Agency (JMA) and the Communication, Ocean, and Meteorological Satellite (COMS). The main instrument of MTSAT-2 is Imager, which is composed of a total of five channels: a visible channel with $1 \mathrm{~km}$ spatial resolution and four infrared channels with $4 \mathrm{~km}$ spatial resolution. JMA developed the algorithm for the detection of CI using MTSAT-2 Imager over Japan, i.e. the rapidly developing cumulus areas (RDCAs) derivation algorithm (Sobajima, 2012). The RDCA algorithm detects CI using several interest fields, but it was only validated during summer 2011 (Sobajima, 2012). The performance of the MTSAT-2 RDCA algorithm needs to be evaluated in different times and circumstances. Han et al. (2015) developed CI detection algorithms for COMS meteorological imager (MI) data by determining new rules and thresholds for the interest fields used in the RDCAs through machine learning, based on the fact that the characteristics of the spectral channels of COMS MI are similar to those of MTSAT-2. The algorithms were validated for various CI cases over Korea, demonstrating good performance with a POD as high as
$75.5 \%$ and a FAR as low as $46.2 \%$. Himawari-8, launched on 7 October 2014, is one of the geostationary satellites operated by JMA. The primary payload of Himawari- 8 is the Advanced Himawari Imager (AHI) which captures the Asia-Pacific region using a 16-channel multispectral imager composed of three visible (blue, green, and red) and 13 IR channels with a spatial resolution of $0.5-2 \mathrm{~km}$ depending on the spectral channel (Bessho et al., 2016). Himawari-8 AHI scans the full disk of the whole Earth, as seen from the satellite $(11000 \times 11000 \mathrm{~km})$, every $10 \mathrm{~min}$. The scan interval for the full disk of Himawari-8 AHI is much shorter than that of MTSAT Imager (60 min) and COMS MI (180 min ; Kim and Ahn, 2014). Furthermore, the spatial and spectral resolutions of Himawari-8 AHI have been substantially improved in comparison to its predecessors. Therefore, Himawari-8 AHI can help enhance the performance of CI detection in northeastern Asia. However, there is no available algorithm for CI detection for Himawari-8 AHI so far. The spectral characteristics of Himawari-8 AHI are comparable to the Advanced Baseline Imager (ABI) integrated into the Geostationary Operational Environmental Satellite-R series (GOES-R) satellites (Schmit et al., 2005), which are a series of geostationary satellites, the first of which will be launched in November 2016 and operated by the National Oceanic and Atmospheric Administration (NOAA). The University of Alabama in Huntsville with NOAA has developed a CI detection algorithm for GOES-R using 12 interest fields designed for the spectral bands of ABI (Walker and Mecikalski, 2011; Walker et al., 2012; Mecikalski et al., 2015). The interest fields of the GOES-R CI algorithm can be directly adopted for Himawari8 AHI. However, the critical threshold values of the interest fields were empirically determined based on simulations and have not been fully assessed due to the lack of ABI-class data sets. This implies that the criteria of the interest fields should be optimized for use with Himawari-8 AHI data.

The existing literature on nowcasting CI has commonly used deterministic approaches which classify clouds as CI and non-CI using the criteria of several interest fields based on simple thresholding approaches (Mecikalski and Bedka, 2006; Mecikalski et al., 2008, 2010; Morel and Senesi, 2002; Sieglaff et al., 2011; Roberts and Rutledge, 2003; Sobajima, 2012). Such deterministic approaches might provide incorrect classification results for unsampled pixels (or objects), especially around the boundaries of CI, increasing the FAR of predictions. Probabilistic approaches produce significantly lower FAR than the deterministic ones through the selection of an appropriate probability threshold (Mecikalski et al., 2015). Mecikalski et al. (2015) developed CI nowcasting algorithms by combining the interest fields derived from GOES and numerical weather prediction (NWP) model data based on probabilistic approaches. They validated the performance of the probabilistic algorithms for CI cases in the United States, resulting in a FAR of $10-18 \%$, which is much lower than the existing deterministic CI detection algorithms for GOES (FAR 48-60\%; Walker et al., 2012). However, 
Table 1. Characteristics of the spectral channels of Himawari-8 AHI.

\begin{tabular}{lrrr}
\hline $\begin{array}{l}\text { No. } \\
\text { band }\end{array}$ & $\begin{array}{r}\text { Central } \\
\text { wavelength } \\
(\mu \mathrm{m})\end{array}$ & $\begin{array}{r}\text { Bandwidth } \\
(\mu \mathrm{m})\end{array}$ & $\begin{array}{r}\text { Spatial } \\
\text { resolution } \\
(\mathrm{km})\end{array}$ \\
\hline 1 & 0.455 & 0.05 & 1 \\
2 & 0.510 & 0.02 & 1 \\
3 & 0.645 & 0.03 & 0.5 \\
4 & 0.86 & 0.02 & 1 \\
5 & 1.61 & 0.02 & 2 \\
6 & 2.26 & 0.02 & 2 \\
7 & 3.85 & 0.22 & 2 \\
8 & 6.25 & 0.37 & 2 \\
9 & 6.95 & 0.12 & 2 \\
10 & 7.35 & 0.17 & 2 \\
11 & 8.60 & 0.32 & 2 \\
12 & 9.63 & 0.18 & 2 \\
13 & 10.45 & 0.30 & 2 \\
14 & 11.20 & 0.20 & 2 \\
15 & 12.35 & 0.30 & 2 \\
16 & 13.30 & 0.20 & 2 \\
\hline
\end{tabular}

Mecikalski et al. (2015) used fewer satellite-based interest fields than the GOES-R CI algorithm due to the limited number of spectral channels of GOES, which implies that it is unknown whether such probabilistic approaches would work for Himawari-8 AHI as well.

In this study, CI detection algorithms for Himawari-8 AHI are developed and validated over the Korean Peninsula in eastern Asia. The objectives of this research were to (1) develop deterministic and probabilistic $\mathrm{CI}$ detection algorithms for Himawari-8 AHI data based on rule-based decision trees and random forest approaches and a logistic regression modelling technique, (2) evaluate the CI detection models in terms of performance and efficiency, (3) assess the strengths and weaknesses of the deterministic and probabilistic CI detection models based on CI cases and validation data sets, and (4) examine key predictor variables for CI detection. This study extends our previous research in Han et al. (2015), where the COMS MI data were used. One of the main limitations of using COMS MI data in the previous study is its relatively coarse spatial resolution $(4 \mathrm{~km})$, which is not enough to detect small convective clouds. The Himawari-8 AHI used in the present study has a higher spatial resolution of $2 \mathrm{~km}$ for IR channels. In addition, the higher spectral (i.e. 16 channels) and temporal (i.e. $10 \mathrm{~min}$ ) resolutions of AHI compared to COMS MI can significantly improve the forecast skill. The present research proposes not only deterministic approaches but also probabilistic ones for CI detection using Himawari8 AHI data. Consequently, the use of advanced geostationary satellite data and various modelling techniques is expected to produce better $\mathrm{CI}$ forecast performance.
Table 2. Convective initiation (CI) cases used to develop and validate the deterministic and probabilistic CI detection models.

\begin{tabular}{llll}
\hline ID & Date & $\begin{array}{l}\text { Time } \\
\text { (hh:mm, UTC) }\end{array}$ & Usage \\
\hline 1 & 13 June 2015 & $09: 40$ & \\
2 & 13 June 2015 & $11: 10$ & \\
3 & 16 June 2015 & $14: 30$ & Training data set \\
4 & 17 June 2015 & $10: 30$ & \\
5 & 4 July 2015 & $06: 30$ & \\
6 & 25 July 2015 & $00: 10$ & \\
7 & 16 August 2015 & $10: 30$ & \\
\hline 8 & 12 June 2015 & $14: 30$ & \\
9 & 1 August 2015 & $07: 50$ & \\
10 & 1 August 2015 & $19: 10$ & \\
11 & 7 August 2015 & $08: 00$ & \\
12 & 30 June 2016 & $08: 40$ & \\
13 & 6 July 2016 & $06: 20$ & \\
14 & 24 July 2016 & $15: 00$ & \\
15 & 1 August 2016 & $06: 20$ & \\
\hline
\end{tabular}

\section{Data}

\subsection{Himawari-8 Advanced Himawari Imager (AHI)}

The specifications of Himawari- 8 AHI are summarized in Table 1. Himawari-8 AHI scans three regions at different levels: the full disk, the Japan area, and the target area. Full disk images are acquired over the whole of the Earth as seen from the satellite every $10 \mathrm{~min}$. Japan area images, collected every $2.5 \mathrm{~min}$, cover the north-eastern and south-western areas of Japan $(3000 \times 3000 \mathrm{~km})$. Himawari-8 AHI also scans a target area of $1000 \times 1000 \mathrm{~km}$ every $2.5 \mathrm{~min}$, which is dedicated to monitoring high-impact meteorological events. In this study, the full disk images were used even though Himawari-8 AHI scans the Japan area four times more often. This is because the Japan area images do not cover the upstream side of storm developments in the East China Sea and western part of the Yellow Sea, which are important areas when forecasting CI over the Korean Peninsula and Japan. The full disk images obtained for 10 cases of CI from June to August 2015 (Table 2) were used to develop and validate the deterministic and probabilistic CI detection models.

\subsection{Weather radar echo and lightning data}

Rainfall with $\geq 35 \mathrm{dBZ}$ precipitation intensity measured by weather radar is known to have significant correlation with the eventual development of cumulonimbus clouds (Mecikalski and Bedka, 2006; Mueller et al., 2003). Therefore, the threshold of $\geq 35 \mathrm{dBZ}$ precipitation intensity has been widely used as the definition of convective events (Mecikalski and Bedka, 2006; Mecikalski et al., 2008, 2010; Roberts and Rutledge, 2003; Walker et al., 2012). In this 


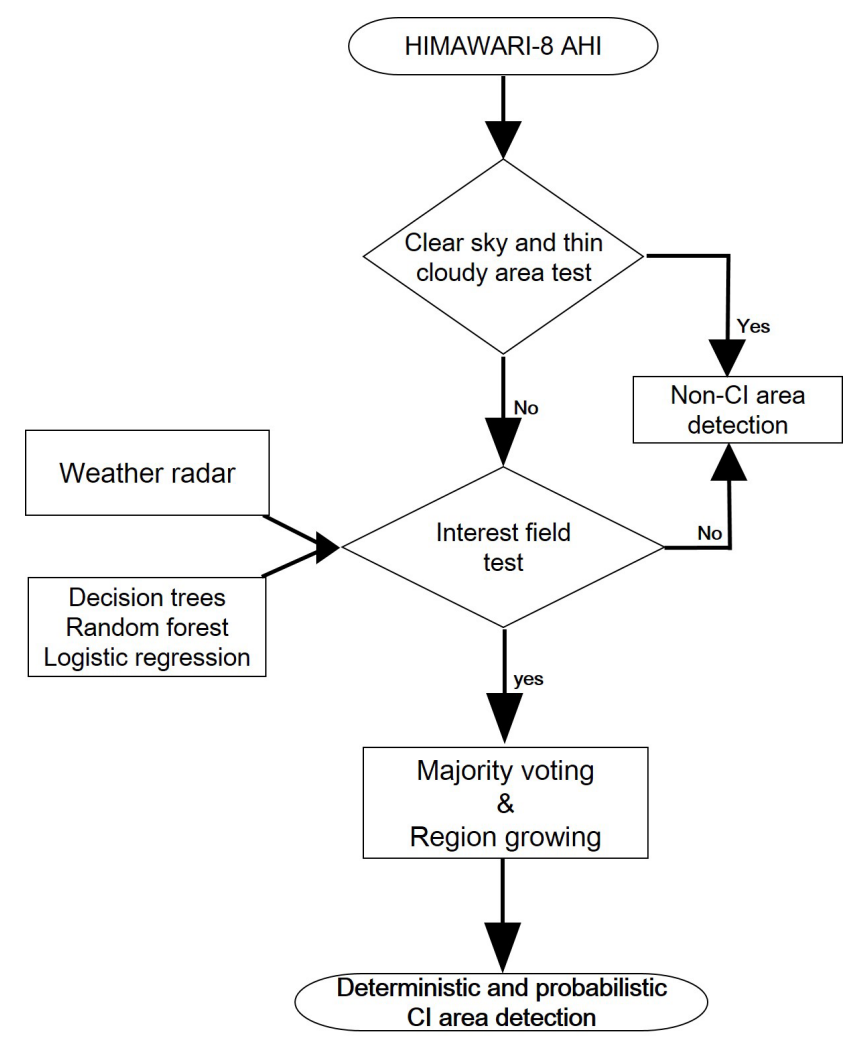

Figure 1. Processing flow of deterministic and probabilistic CI detection based on machine learning and statistical methods.

study, the first occurrence of rainfall with $\geq 35 \mathrm{dBZ}$ precipitation intensity was defined as CI. KMA has operated a total of 10 weather radars in South Korea. They have produced plan position Indicator (PPI) in which the precipitation echoes measured at a given elevation angle are projected on a plane every $10 \mathrm{~min}$ and constant altitude PPI (CAPPI) images, which are calculated using several PPI elevations. A $1.5 \mathrm{~km}$ CAPPI with mosaic image was used to determine the area and time of each CI occurrence. Since the effective radius of the $1.5 \mathrm{~km}$ CAPPI is about $100 \mathrm{~km}$, only the $1.5 \mathrm{~km}$ CAPPI echo at each radar within $100 \mathrm{~km}$ was used.

Lightning observation data were used as supplementary data for validating the CI detection results, especially for ocean areas. The lightning data were provided by KMA, which has operated a ground-based Total Lightning Detection System (TLDS) since 2001. The TLDS has an average accuracy of $90 \%$ for lightning detection, with locational accuracy of $500 \mathrm{~m}$ over the land and $2 \mathrm{~km}$ over the ocean (Kar and Ha, 2003). The TLDS lightning observation data during the same period were used with the ground radar measurements for the validation of the CI detection models.

\section{Methods to detect CI using geostationary satellite data}

Because of the large similarity in spectral channels between Himawari-8 AHI and GOES-R ABI, the GOES-R CI algorithm might be adopted and tuned to develop $\mathrm{CI}$ algorithms for Himawari-8 AHI. The interest fields from GOES-R CI algorithm and threshold values have not been validated for Himawari-8 AHI. In order to develop more objective CI models for Himawari-8 AHI, rule-based decision trees and random forest machine learning approaches were used as well as a logistic regression model. The interest fields identified in the GOES-R CI algorithm were used as predictor variables in both deterministic and probabilistic approaches. The processing flow diagram of the proposed CI detection approaches is shown in Fig. 1. Since pixel-based CI detection is known to often result in salt-and-pepper noise and non-compact CI output (Han et al., 2015), the proposed approaches include postprocessing to minimize such problems.

\subsection{Interest fields of GOES-R Advanced Baseline Imager (ABI) CI algorithm}

The interest fields of the GOES-R ABI CI algorithm (Table 3) were used as a set of predictors to develop the deterministic and probabilistic CI detection models for Himawari8 AHI. All the interest fields are calculated only from IR channels in order to predict CI using both daytime and nighttime images. $T_{\mathrm{b}}$ measured at $11.2 \mu \mathrm{m}$ and its time trend represent cloud-top temperature and cloud-top cooling rate, respectively (Mecikalsk and Bedka, 2006; Mecikalski et al., 2010; Walker and Mecikalski, 2011). The interest fields from spectral differences provide information on cloud-top height (cloud depth) and glaciation at the time of image, while those from temporal differences provide information on the rate of vertical cloud-top growth.

Prior to the calculation of the interest fields, cloudless and cirrus regions were masked out from Himawari-8 AHI images using the criteria of the $T_{\mathrm{b}}$ at $11.2 \mu \mathrm{m}$-channel $<288.5 \mathrm{~K},-3 \mathrm{~K}<12.4-11.2 \mu \mathrm{m}$-channels difference $<3 \mathrm{~K}$, and $-3 \mathrm{~K}<$ the trispectral difference $<3 \mathrm{~K}$. Such criteria have been empirically used to identify clear sky and thin clouds in summer by KMA. The first criterion was used to remove land surface and cirrus from AHI images, while the others were employed to remove clear-sky areas. To determine the timedependent interest fields, it is essential to track the motion of cloud objects. A simple temporal overlap object tracking method (Walker and Mecikalski, 2011) was adopted in this study, which uses two consecutively obtained AHI images in order to track cloud objects. This object tracking method has a weakness: fast moving cloud objects of small size might not be traced. However, the frequent scanning interval and fine spatial resolution of Himawari-8 AHI help mitigate the weakness of the tracking method. The motion of cloud objects was traced from two consecutive $11.2 \mu \mathrm{m}$-channel im- 
Table 3. Summary of the interest fields to develop convective initiation (CI) detection models used in this study (Walker and Mecikalski, 2011).

\begin{tabular}{lll}
\hline ID & Interest field & Contribution \\
\hline 1 & $11.2 \mu \mathrm{m} T_{\mathrm{b}}$ & Cloud-top temperature assessment \\
\hline 2 & $\begin{array}{l}6.2-11.2 \mu \mathrm{m} \\
6.2-7.3 \mu \mathrm{m}\end{array}$ & Cloud-top height relative to tropopause \\
4 & $13.3-11.2 \mu \mathrm{m}$ & \\
\hline 5 & $12.3-11.2 \mu \mathrm{m}$ & Cloud-top glaciation \\
6 & $8.6-11.2 \mu \mathrm{m}$ & \\
\hline 7 & $11.2 \mu \mathrm{m}$ time trend & Cloud-top cooling rate \\
\hline 8 & $6.2-11.2 \mu \mathrm{m}$ time trend & Temporal changes in cloud-top height \\
9 & $6.2-7.3 \mu \mathrm{m}$ time trend & \\
10 & $12.3-11.2 \mu \mathrm{m}$ time trend & Cloud-top glaciation \\
\hline 11 & $(8.6-11.2 \mu \mathrm{m})-(11.2-12.3 \mu \mathrm{m})$ & Temporal changes in cloud-top glaciation \\
\hline 12 & $(8.6-11.2 \mu \mathrm{m})-(11.2-12.3 \mu \mathrm{m})$ time trend &
\end{tabular}

ages of AHI and then the time-dependent interest fields were calculated.

\subsection{Deterministic and probabilistic approaches for CI detection}

The event of CI (i.e. CI vs. non-CI) is used as a dependent (i.e. response) variable in the $\mathrm{CI}$ detection models and is based on deterministic and probabilistic approaches. For seven Himawari-8 AHI images, including CI events over the Korean Peninsula, the pixels within cloud objects corresponding to the first occurrence of $\geq 35 \mathrm{dBZ}$ precipitation intensity were extracted and considered convective clouds (CI areas). The other clouds were identified as non-CI regions. In order to collect interest field samples to develop CI detection models, each CI and non-CI area was tracked through a visual interpretation of the $11.2 \mu \mathrm{m}$-channel images obtained $10-60$ min before the first occurrence of $\geq 35 \mathrm{dBZ}$ precipitation intensity, rather than using the temporal overlap object tracking method (Zinner et al., 2008) that was used to calculate the time-dependent interest fields. A total of 3204 CI reference data (1324 CI and 1880 non-CI samples) were extracted from the AHI images and used to train and validate the deterministic and probabilistic CI detection models. From $8 \%$ of the total images (42 scenes), 1060 CI samples and 1504 non-CI samples were extracted and used as training data, while $264 \mathrm{CI}$ samples and 376 non-CI samples extracted from the remaining AHI images (18 scenes) were used to validate the models. The models were further validated using 3 additional CI events, which were not used to extract samples.

In this study, three approaches including decision trees (DT), random forest (RF), and logistic regression (LR) were used for the development of CI detection models. DT and LR were used for deterministic and probabilistic CI detection, respectively. Meanwhile, RF was used for both deterministic and probabilistic detection of CI. DT has been widely used for classification and regression tasks in the remote sensing field (Li et al., 2013; Lu et al., 2014; Kim et al., 2014; Torbick and Corbiere, 2015). See5, developed by RuleQuest Research, Inc. (Quinlan, 2015), was employed to perform the DT-based classification of clouds into CI and non-CI. See5 works by repeatedly splitting samples into two groups of greater homogeneity using an entropy-based parameter to generate a tree (Quinlan, 2015; Jensen and Im, 2007). Pruning to avoid overfitting is often applied when a decision tree is generated. One of the merits of See 5 compared to other DT algorithms is that the generated tree can be reproduced with multiple if-then rules, which makes it easier to interpret the results than the original tree (Jensen et al., 2007; Rhee et al., 2008; Im et al., 2012, 2008; Kim et al., 2015).

RF uses a bootstrapping strategy from the original training data to produce a series of Classification and Regression Trees (CART) that is a non-parametric decision tree, which produces either classification or regression trees depending on whether the dependent variable is categorical or numerical (i.e. continuous; Breiman, 2001). The numerous independent trees (e.g. 500, 1000) are grown based on two randomizations including (1) a randomly selected subset of the training samples for each tree and (2) a randomly selected subset of input variables at each node of the tree. This way, RF overcomes the well-known limitation of CART, in that results are sensitive to the configuration and quality of training data (Lawrence and Wright, 2001; Rhee et al., 2014; Guo and $\mathrm{Du}, 2017)$. Thus, $\mathrm{RF}$ has recently gained popularity in remote sensing classification and regression (Kim et al., 2014; Li et al., 2014; Liu et al., 2015; Lu et al., 2013; Park et al., 2016; Yoo et al., 2012). Two approaches are generally adopted to 
reach a final conclusion from the independent decision trees including a simple majority voting and weighted majority voting strategy for classification, while a final value is either simply averaged from the results of the multiple regression trees or averaged with weights for regression. In the probabilistic RF, the probability of an event occurrence is calculated using the ratio of voting for $\mathrm{CI}$ and non-CI cases with 500 trees.

LR is one of the statistical regression methods that is used for modelling a categorical dependent variable using independent variables (Hosmer and Lemeshow, 2000; Nyarko et al., 2015). In this study, binary LR, a type of LR technique that deals with only two values for a dependent variable, was used to estimate the probability of CI occurrence. The logistic function is given as follows:

$$
E(Y)=\frac{1}{1+\exp \left[-\left(\beta_{0}+\sum_{j=1}^{k} \beta_{j} X_{j}\right)\right]} \text {, }
$$

where $E$ is the expected value of the dependent variable $Y, k$ is the number of independent variables and $X_{j}$ is the value of the $j$ th independent variable, $\beta_{0}$ is the intercept from the linear regression equation, and $\beta_{j}$ is the weighting coefficient for the $j$ th independent variable. The logistic function produces $E$ values of $[0,1]$ which are used as the probability of whether CI will occur or not. DT, RF, and LR provide the relative importance of input variables when developing models such as attribute usage, mean decrease accuracy, and the absolute value of weighting coefficients, respectively. See5 produces information on how frequently each variable is used in the results. RF calculates the decrease in accuracy of the model using out-of-bag data through the random permutation of a variable. Therefore, a higher mean decrease accuracy of a variable indicates a larger contribution from the variable to develop a model. In the LR, the exponentiation of weighting coefficients of the independent variables reflects the relative importance of the variables, which refers to the changes in the odds ratio attributed to an input variable.

A series of typical accuracy metrics were calculated through confusion matrices to assess the performance of the CI detection models, including producers' and users' accuracies, overall accuracy, and kappa coefficients. In addition, the prediction results of the models were further assessed for the 3 cases of CI events over the Korean Peninsula by computing POD, FAR, overall accuracy (OA), and critical success index (CSI) reflecting effects of both POD and FAR as follows (Mecikalski et al., 2015):

$$
\begin{aligned}
\mathrm{POD} & =A /(A+B) \\
\mathrm{FAR} & =C /(A+C) \\
\mathrm{OA} & =(A+D) /(A+B+C+D) \\
\mathrm{CSI} & =(A) /(A+B+C),
\end{aligned}
$$

where $A$ is the number of CI objects that are correctly detected as CI (i.e. hits), $B$ is the number of CI objects in- correctly classified as non-CI (i.e. misses), $C$ is the number of non-CI objects incorrectly identified as CI (i.e. false alarm), and $D$ indicates correct negatives. $A$ through $D$ were counted from the results of the CI detection models using the Himawari-8 AHI images obtained 0-10, 10-20, 20-30, 3040 , and 40-50 min before the first occurrence of $\geq 35 \mathrm{dBZ}$ intensity from the weather radar data based on CI objects. In order to identify $\mathrm{CI}$ objects in the $\mathrm{AHI}$ images that were obtained 0-50 min before the $\mathrm{CI}$ event occurred, distances from cloud objects to the location of the CI occurrence (i.e. $\geq 35 \mathrm{dBZ}$ precipitation intensity) were calculated using the atmospheric motion vector (AMV) product generated hourly from COMS MI (as Himawari-8 AHI does not provide AMV yet), assuming that the velocity and direction of moving clouds were constant over $1 \mathrm{~h}$. Mean velocities and directions of the AMV of each cloud object for each case day were used to identify an overall motion vector. The cloud objects with a given direction within a given distance from the location of the first occurrence of $\geq 35 \mathrm{dBZ}$ precipitation intensity were considered CI. Overall POD, FAR, OA, and CSI for each CI detection model were computed based on the $A-D$ values of 3 case days.

For the 3 case days, the lead time for CI detection was calculated using a weighted mean depending on A (i.e. hits). The mean was detected from the AHI images and obtained before precipitation intensity exceeds $35 \mathrm{dBZ}$, as follows (Han et al., 2015):

$$
\frac{\sum A_{t} \times n}{\sum n}(t=0,10,20,30,40,50,60 \mathrm{~min}),
$$

where $A_{t}$ is the number of $A$ counted from the AHI images obtained $t$ minutes before the first occurrence of $\geq 35 \mathrm{dBZ}$ intensity, and $n$ is the number of $A_{t}$. The lead time of each CI detection model was determined using the $A_{t}$ and $n$ of all case days.

\subsection{Postprocessing of CI cloud objects}

Similar to the existing studies (citations), pixel-based CI detection models were developed in this study. However, pixel-based CI detection has some drawbacks. First, salt-andpepper noise with one to three pixels often occurs, which is not related to CI cloud clusters. Second, although CI clouds are typically compact, non-compact CI cloud objects are sometimes detected due to rough cloud tops. In order to minimize these problems, two techniques were adopted - majority filtering and region growing. We tested different window sizes (from 2 to 5 pixels) for majority filtering, and determined a $2 \times 2$ window as the optimum size based on a visual inspection of the resultant CI cloud objects. If there were only one or two CI pixels in the $2 \times 2$ window, the CI pixels were excluded. Otherwise (i.e. more than two CI pixels), all pixels were considered as CI pixels. After the majority filtering, region growing was conducted to make the detected CI cloud objects more compact and aggregated. Re- 
Table 4. Assessment of the DT model for CI detection using the test data.

\begin{tabular}{lrrrr}
\hline & \multicolumn{4}{c}{ Reference } \\
\cline { 2 - 5 } Classification & CI & Non-CI & Sum & $\begin{array}{r}\text { User's } \\
\text { accuracy }\end{array}$ \\
\hline CI & 239 & 21 & 260 & $91.92 \%$ \\
Non-CI & 26 & 355 & 381 & $93.18 \%$ \\
Sum & 265 & 376 & 641 & \\
Producer's accuracy & $90.19 \%$ & $91.41 \%$ & \\
Overall accuracy & \multicolumn{4}{c}{$92.67 \%$} \\
Kappa coefficient & \multicolumn{5}{c}{$84.84 \%$} \\
\hline
\end{tabular}

Table 5. Assessment of the RF model for CI detection using the test data.

\begin{tabular}{lrrrr}
\hline & \multicolumn{4}{c}{ Reference } \\
\cline { 2 - 5 } Classification & CI & Non-CI & Sum & $\begin{array}{r}\text { User's } \\
\text { accuracy }\end{array}$ \\
\hline CI & 245 & 11 & 256 & $95.70 \%$ \\
Non-CI & 20 & 365 & 385 & $94.81 \%$ \\
Sum & 265 & 376 & 641 & \\
Producer's accuracy & $92.45 \%$ & $97.07 \%$ & \\
Overall accuracy & \multicolumn{4}{c}{$94.27 \%$} \\
Kappa coefficient & \multicolumn{5}{c}{$89.98 \%$} \\
\hline
\end{tabular}

gion growing has been widely used to segment images to produce objects (i.e. homogeneous regions) in the field of remote sensing. The basic concept of region growing is to examine neighbouring pixels from seed pixels and determine whether they should be added to the region of a seed (citations). In this study, CI pixels were designated as seed points and $T_{\mathrm{b}}$ at $11.2 \mu \mathrm{m}$ was used as a background field to examine the homogeneity of regions. Regions grow while the difference between the temperature averaged within a region and temperature at a neighbouring pixel is less than 0.5 , which is empirically determined. This postprocessing was conducted to reduce salt-and-pepper noise and FAR for CI detection.

\section{Performance and validation of CI detection models}

\subsection{Performance of CI detection models with postprocessing}

The box plots of the 12 interest fields generated using CI and non-CI reference data are depicted in Fig. 2. A line inside a coloured box indicates the median value of the data. The height of the coloured boxes represents the interquartile range of the data, and 1.5 times the interquartile range is shown with the vertical centre lines. The dots above and below the vertical lines are outliers. The $p$ values in the upper left corner of each box plot were derived from $t$ test at the
Table 6. Assessment of the probabilistic RF model for CI detection using the test data set. CI probabilities above $50 \%$ are considered CI.

\begin{tabular}{lrrrr}
\hline & \multicolumn{4}{c}{ Reference } \\
\cline { 2 - 5 } Classification & CI & Non-CI & Sum & $\begin{array}{r}\text { User's } \\
\text { accuracy }\end{array}$ \\
\hline CI & 242 & 13 & 255 & $94.90 \%$ \\
Non-CI & 23 & 363 & 386 & $94.04 \%$ \\
Sum & 265 & 376 & 641 & \\
Producer's accuracy & $91.32 \%$ & $96.54 \%$ & & \\
Overall accuracy & \multicolumn{4}{c}{$94.38 \%$} \\
Kappa coefficient & \multicolumn{5}{c}{$88.36 \%$} \\
\hline
\end{tabular}

$95 \%$ confidence level. All the interest fields except for 6.2 $7.3 \mu \mathrm{m}$ time trend $T_{\mathrm{b}}$ showed $p$ values below 0.05 . In particular, the interest fields of $11.2,6.2-11.2$, and $6.2-7.3 \mu \mathrm{m} T_{\mathrm{b}}$ showed noticeably low $p$ values $(<0.001)$, of which the interquartile ranges of $\mathrm{CI}$ and non-CI samples do not overlap with each other.

The performances of the four CI detection models were assessed using confusion matrices produced from the test data set (Tables 4-7). Since the probabilistic models produce the possibility of $\mathrm{CI}$ occurrence ranging from 0 to $100 \%$, the pixels with a probability higher than $50 \%$ were regarded as the predicted $\mathrm{CI}$ areas in order to produce the confusion matrices. Out of the four CI detection models, the deterministic RF model showed the highest overall accuracy (94.27\%) and kappa coefficient $(89.28 \%)$. The higher performance of deterministic RF compared to DT (overall accuracy of $92.67 \%$ and kappa coefficient of $84.84 \%$ ) can possibly be attributed to randomization strategies of deterministic RF such as bootstrap aggregating and randomized node optimization which can reduce variance and overfitting when building decision trees. The overall accuracy and kappa coefficient value of the probabilistic RF model (94.27 and $89.98 \%$, respectively) were similar to those of the deterministic RF model because the same randomization strategies were used in the two models. The LR model showed an inferior performance in terms of overall accuracy and kappa coefficient (90.63 and $80.72 \%$, respectively), possibly due to the limited capability of the model to handle the non-linear behaviour of the data (Tu, 1996; Table 6). However, these accuracies could not be generalized using the test data set to predict real CI cases.

The relative importance of the interest fields that were used for CI detection and identified by DT are shown in Fig. 3, along with the deterministic RF. The $11.2 \mu \mathrm{m} T_{\mathrm{b}}$, representing cloud top temperature, was identified as the most contributing interest field for the discrimination of the two classes (i.e. CI and non-CI) in both DT and deterministic RF models. This corresponds well with the findings of Mecikalski et al. (2015), which used 25 satellite-based and numerical weather prediction (NWP)-based interest fields to 

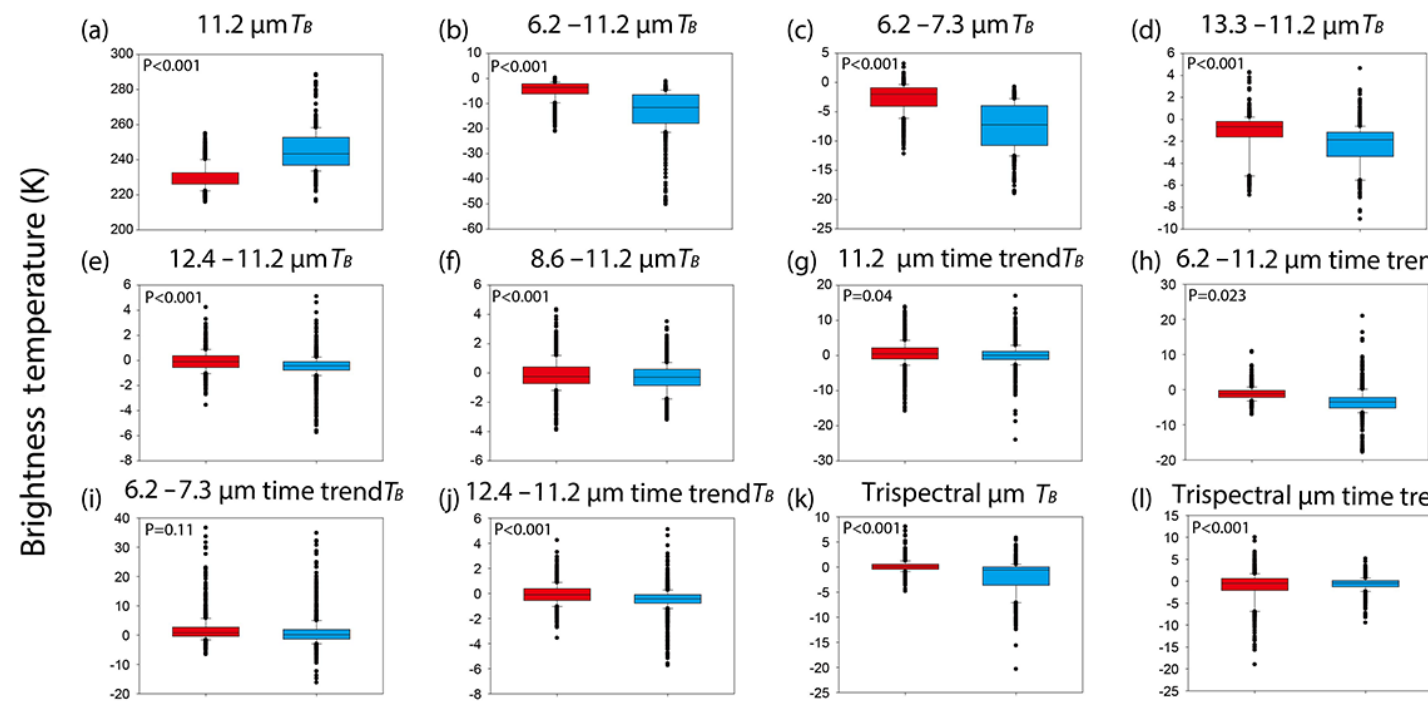

(g) $11.2 \mu \mathrm{m}$ time trend $T_{B}$

(h) $6.2-11.2 \mu \mathrm{m}$ time trend $T_{B}$
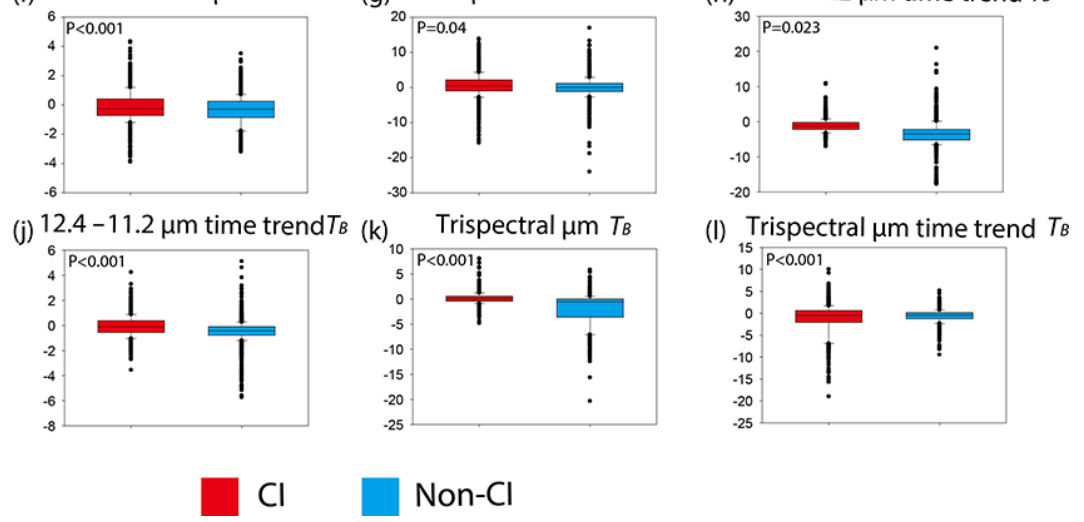

Non-Cl

Figure 2. Box plots of 12 input variables (i.e. interest fields) generated based on the reference data used for CI detection models: (a) $11.2 \mu \mathrm{m}$ $T_{\mathrm{b}}$, (b) $6.2-11.2 \mu \mathrm{m} T_{\mathrm{b}}$, (c) $6.2-7.3 \mu \mathrm{m} T_{\mathrm{b}}$, (d) $13.3-11.2 \mu \mathrm{m} T_{\mathrm{b}}$, (e) 12.4-11.2 $\mu \mathrm{m} T_{\mathrm{b}}$, (f) $8.6-11.2 \mu \mathrm{m} T_{\mathrm{b}}$, (g) $11.2 \mu \mathrm{m}$ time trend $T_{\mathrm{b}}$, (h) $6.2-$ $11.2 \mu \mathrm{m}$ time trend $T_{\mathrm{b}}$, (i) $6.2-7.3 \mu \mathrm{m}$ time trend $T_{\mathrm{b}}$, (j) $12.4-11.2 \mu \mathrm{m}$ time trend $T_{\mathrm{b}}$, (k) tri-spectral $\mu \mathrm{m} T_{\mathrm{b}}$, (l) tri-spectral $\mu \mathrm{m}$ time trend $T_{\mathrm{b}}$.

Table 7. Assessment of the LR model for CI detection using the test data set. CI probabilities above $50 \%$ considered as a CI.

\begin{tabular}{lrrrr}
\hline & \multicolumn{4}{c}{ Reference } \\
\cline { 2 - 5 } Classification & CI & Non-CI & Sum & $\begin{array}{r}\text { User's } \\
\text { accuracy }\end{array}$ \\
\hline CI & 237 & 33 & 270 & $82.78 \%$ \\
Non-CI & 27 & 343 & 370 & $92.70 \%$ \\
Sum & 264 & 376 & 640 & \\
Producer's accuracy & $89.77 \%$ & $91.22 \%$ & \\
Overall accuracy & \multicolumn{4}{c}{$90.63 \%$} \\
Kappa coefficient & \multicolumn{4}{c}{$80.72 \%$} \\
\hline
\end{tabular}

predict CI and identified cloud top temperature as the most contributing satellite-derived variable. The next contributing variables in both DT and deterministic RF models were 13.3$11.2 \mu \mathrm{m} T_{\mathrm{b}}$ and the trispectral difference time trend (Fig. 3). The interest field of $13.3-11.2 \mu \mathrm{m} T_{\mathrm{b}}$ is closely related to cloud top height, which increases as cloud objects evolve into convective ones. Meanwhile, the trispectral difference time trend, representing the temporal variation of the cloud-top glaciation, increases during the growth of convective clouds. The interest field of $6.2-7.3 \mu \mathrm{m} T_{\mathrm{b}}$ time trend, the only variable showing a $p$ value greater than 0.05 , was defined as the least contributing interest field in the DT-based CI detection model and the second least one in the deterministic RF model. The relative importance of the interest fields for the LR-based CI detection model can be evaluated using the
Table 8. Exp (b) values from the logistic regression (LR) model, which are odds ratios derived by SPSS at the significance level $95 \%$.

\begin{tabular}{lr}
\hline Interest field & Exp (b) \\
\hline$(8.6-11.2 \mu \mathrm{m})-(11.2-12.4 \mu \mathrm{m})$ & 2.190 \\
$12.4-11.2 \mu \mathrm{m}$ time trend & 1.456 \\
$6.2-11.2 \mu \mathrm{m}$ & 1.146 \\
$13.3-11.2 \mu \mathrm{m}$ & 1.059 \\
$6.2-7.3 \mu \mathrm{m}$ time trend & 0.979 \\
$(8.6-11.2 \mu \mathrm{m})-(11.2-12.4 \mu \mathrm{m})$ time trend & 0.979 \\
$6.2-7.3 \mu \mathrm{m}$ & 0.923 \\
$12.4-11.2 \mu \mathrm{m}$ & 0.802 \\
$11.2 \mu \mathrm{m}$ & 0.670 \\
$11.2 \mu \mathrm{m}$ time trend & 0.585 \\
$8.6-11.2 \mu \mathrm{m}$ & 0.483 \\
$6.2-11.2 \mu \mathrm{m}$ time trend & 0.348 \\
\hline
\end{tabular}

values of the $\operatorname{Exp}(\mathrm{b})$ that are listed in Table 8 . The variable of trispectral difference, $(8.6-11.2 \mu \mathrm{m})-(11.2-12.4 \mu \mathrm{m})$, has the highest value of the $\operatorname{Exp}(b), 2.190$, which means the probability that a pixel is an actual CI increases by 2.19 times per 1 $\mathrm{K}$ increase in the trispectral difference. The 6.2-11.2 $\mu \mathrm{m}$ time trend $(\operatorname{Exp}(b)=0.348)$ was also identified as a contributing variable in the LR model, which decreases the probability that a pixel is an actual CI by $65.2 \%$ per $1 \mathrm{~K}$ decrease in the $6.2-11.2 \mu \mathrm{m}$ time trend. These two important variables in the LR model, however, were not ranked high on the variable importance determined by the DT and RF models. The 
(a)

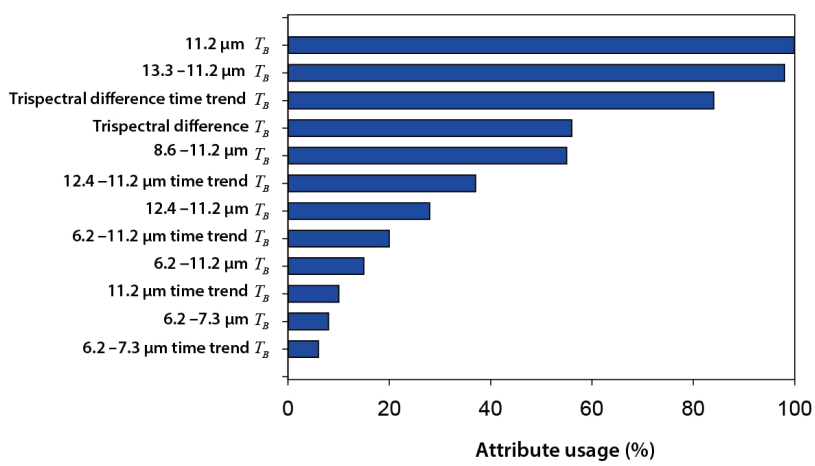

(b)

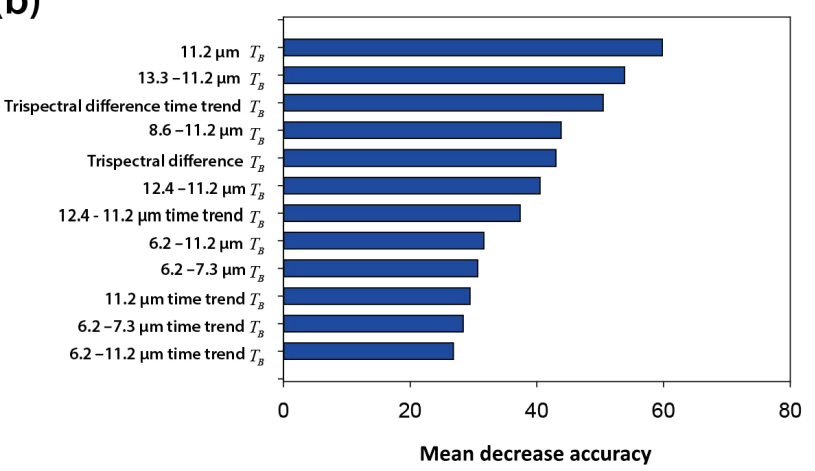

Figure 3. (a) Attribute usage information in percentage by interest field produced in the DT model. (b) Mean decrease accuracy (MDA) in percentage by interest field produced in the RF model. MDA was calculated using out-of-bag (OOB) data when an interest field was randomly permuted. The higher the MDA of an interest field, the more the field contributes to identify CI.

6.2-11.2 $\mu \mathrm{m}$ time trend was even identified as the least contributing variable in the RF model.

As convective clouds grow vertically in the troposphere (Jorgensen and LeMone, 1989; Trier et al., 2004; Rosenfeld et al., 2008; Sieglaff et al., 2010), time trend variables that represent the vertical growth of clouds might be useful to detect CI. However, the time trend variables among the interest fields here resulted in relatively lower contributions in both DT and RF models. A simple overlap method using two temporally consecutive images was used to determine the temporal change of clouds instead of AMV, which has been widely used to track clouds, because AMV is not yet available for Himawari-8. This may result in a somewhat inaccurate estimation of the vertical growth of clouds. Thus, the incorporation of AMV from Himawari-8 in the models may improve the performance of CI detection.

Figure 4 shows CI detection results before and after the two postprocesses. Incorrectly detected small CI pixels (Fig. 4a, c) were removed through the majority voting. In addition, the CI objects had a more compact shape with a few holes (Fig. 4b, d) and were growing throughout the region. (a)

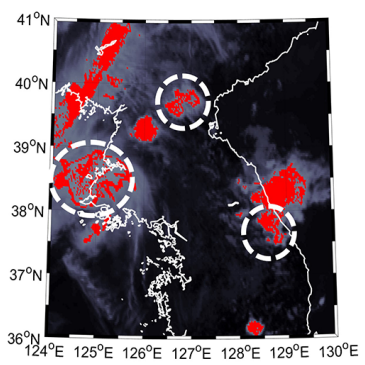

(c)

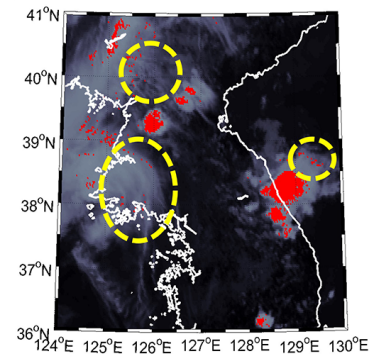

(b)

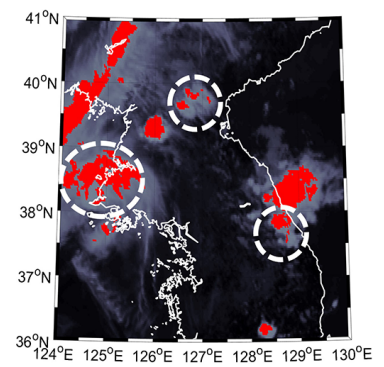

(d)

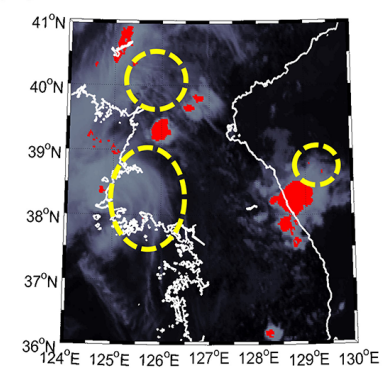

Figure 4. Before and after postprocessing of CI cloud objects using majority voting and region growing. (a) An example of deterministic CI detection generated by DT before postprocessing. (b) Deterministic CI detection generated by DT after postprocessing. (c) Deterministic CI detection generated by RF before postprocessing. (d) Deterministic CI detection generated by RF after postprocessing. While dashed white circles show that region growing made CI objects more compact with few holes, dashed yellow circles show that majority voting effectively removed salt-and-pepper noise.

This postprocessing resulted in decreasing FAR and increasing POD by making CI objects grow and merge, which is discussed in the next subsection.

Figure 5 depicts the accuracy metrics before and after postprocessing - majority voting and region growing. The figure clearly shows that the postprocessing led to an increase of POD and decrease of FAR. In particular, FAR decreased about $4 \%$ after the postprocessing was applied when lightning data were used for validation. Higher POD and lower FAR resulted in higher OA and CSI, which implies that the proposed postprocessing was effectively used to improve the performance of the $\mathrm{CI}$ detection models.

\subsection{Validation of three CI cases with ground radar and lightning data.}

The four CI detection models were applied to the eight cases of $\mathrm{CI}$ events over the Korean Peninsula and validated using two types of reference data sets (i.e. weather radar and lightning observations). Figures 6 and 7 show the validation metrics of the models based on each reference data set. Figure 8 represents averaged lead time for each validation by model.

Overall, DT produced the highest POD values regardless of the reference data used (i.e. for both lightning and ground 
(a)

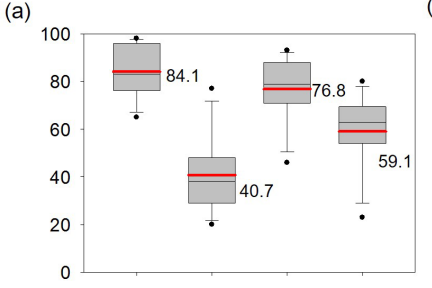

(c)

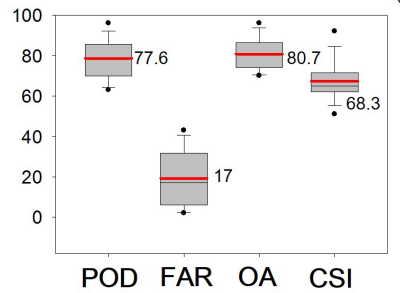

(b)

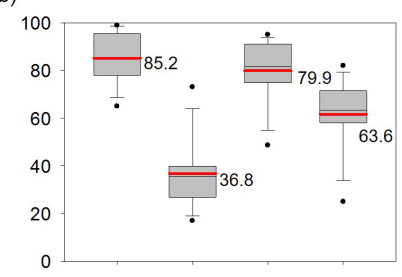

(d)

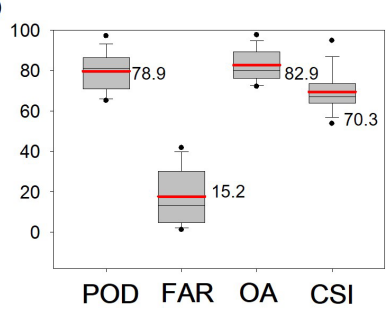

Figure 5. Quantitative assessment based on deterministic RF before and after postprocessing. (a) Validation metrics of RF using lightning data before postprocessing. (b) Validation metrics of RF using lightning data after postprocessing. (c) Validation metrics of RF using radar CAPPI data before postprocessing. (d) Validation metrics of RF using radar CAPPI data after postprocessing. The values next to boxes correspond to the average metric values as a percentage.

radar). However, it overpredicted CI objects, which resulted in high FAR. Although RF yielded slightly lower POD than DT when lightning data were used, RF showed much lower FAR than DT, which led to higher OA and CSI than DT (Fig. 6). On the other hand, when ground radar was used for validation, since FAR was calculated considering the effective radius of the radar, RF produced FAR similar to that of DT, which resulted in higher OA for DT than RF (Fig. 7).

There is not much difference in FAR values between DT and RF when radar reference data were used. However, CI objects produced from DT tended to be largely scattered through visual inspection of the results, which may result in confusion to the users of CI product (i.e. forecasters). For probabilistic RF and LR models, $50 \%$ was used as a threshold to detect CI. Both produced relatively lower FAR and POD values than DT. Although the threshold to detect CI can be optimized for probabilistic RF and LR models to improve the performance, it is beyond the scope of this research. Considering both results used lightning and ground radar data, $\mathrm{RF}$ appeared to be the best CI detection model, which can be confirmed by the averaged CSI values (Figs. 6 and 7). Since lead time is calculated based on hits, DT mostly produced the longer averaged lead time than the other three models (Fig. 8). However, when radar data were used for validation, the difference in averaged lead time between DT and RF was less than $1 \mathrm{~min}$.

Mecikalski et al. (2015) used $50 \%$ as the threshold to identify CI from the results of probabilistic RF and LR and showed results similar to ours, which are depicted in Fig. 7, i.e. a slightly better performance by probabilistic RF than LR. Unlike Mecikalski et al. (2015), who used 9 channels

(a)

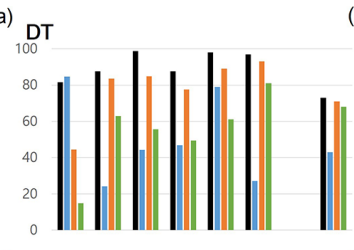

(c)

c) ${ }_{100}$ rob RF

(b) $\mathrm{RF}$

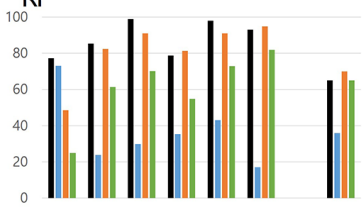

(d) LR
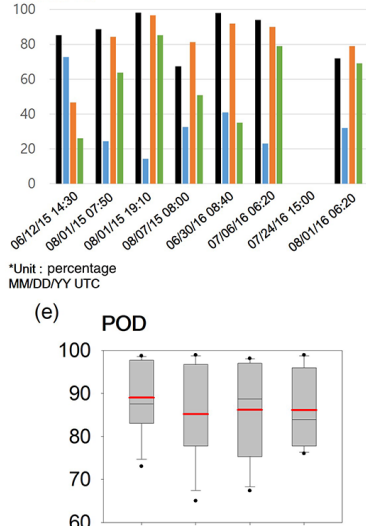

(g)
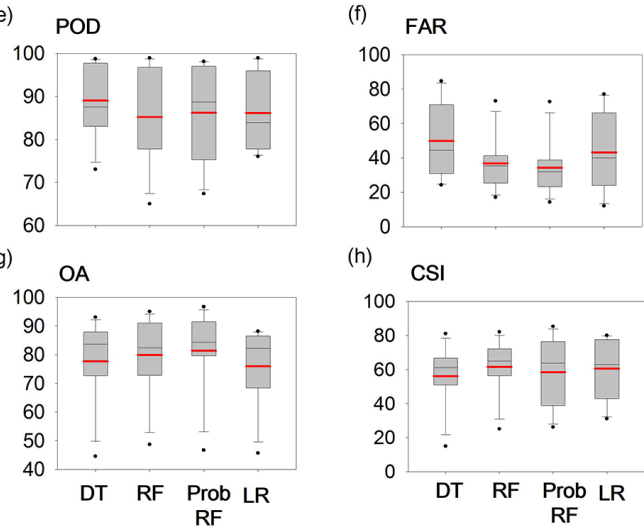

(h)

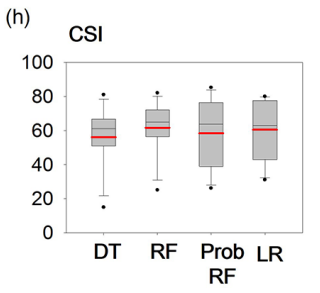

Figure 6. Validation metrics based on lightning data for the (a) deterministic DT and (b) RF, (c) probabilistic RF, and (d) LR models. Box plots of validation metrics based on lightning data for (e) POD, (f) FAR, (g) OA, and (h) CSI. While red lines in the boxes represent mean values, grey lines represent median values.

of GOES satellite data as well as 16 NWP model data, this present study solely focused on using satellite data Himawari-8 AHI channels. Although it is not possible to directly compare our results to others' as different input and reference data were used, this present study showed good results that are comparable with Mecikalski et al. (2015). This implies that Himawari- 8 satellite data (or future weather satellites with similar/more advanced specifications) can be solely used to detect CI, which enables the development of operational CI detection algorithms with high POD and low FAR. However, model results such as convective available potential energy (CAPE), convective inhibition (CIN), and vertical shear $(0-6 \mathrm{~km})$ can be effectively used to reduce FAR in the proposed $\mathrm{CI}$ detection algorithms.

Figure 9 shows $\mathrm{CI}$ areas for the case of $\mathrm{CI}$ events on $7 \mathrm{Au}$ gust 2015 at 07:50 (UTC) predicted by the DT, deterministic RF, probabilistic RF, and LR models, respectively. All models showed better performance in terms of FAR, OA, and CSI based on the weather radar observations rather than the lightning observations. This is because the number of CI objects 


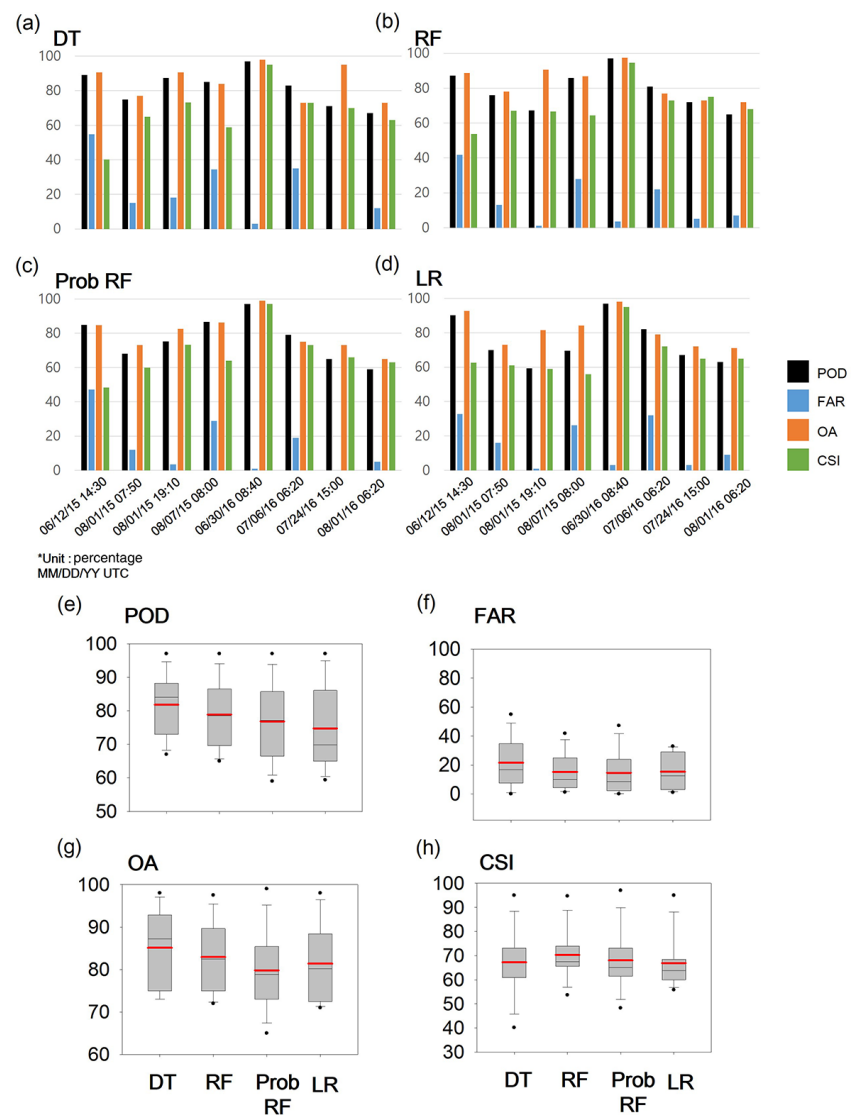

Figure 7. Validation metrics based on radar CAPPI data for the (a) deterministic DT and (b) RF, (c) probabilistic RF, and (d) LR models. Box plots of validation metrics based on radar CAPPI data for (e) POD, (f) FAR, (g) OA, and (h) CSI. While red lines in the boxes represent mean values, grey lines represent median values.

detected by the radar is smaller than that by the lightning observations due to the limited effective radius, similar to the case on 12 June. The DT and deterministic RF models detected CI areas around the north-western Korean peninsula. Such predicted CI areas might be correct despite the lack of lightning observations, but the weather radar data from China Meteorological Administration (CMA) has not been available over the region and hence we were not able to confirm whether the CI objects were correctly identified. CI events on 30 June 2016 at 08:40 (UTC) were depicted in Fig. 10. The DT and LR models over-detected CI objects, which resulted in high FAR. While FAR based on radar data was much lower than when based on lightning data, the averaged lead time based on lightning data was longer than when based on radar data because there were missing CI objects in radar echoes above $35 \mathrm{dBZ}$ around the latitude of $38^{\circ} \mathrm{N}$ and longitude of $128.5^{\circ} \mathrm{E}$.

CI occurrence on 6 July 2016 at 05:30 (UTC) was shown in Fig. 11. All models were not able to detect CI events which occurred around the west coast of Korean Peninsula,

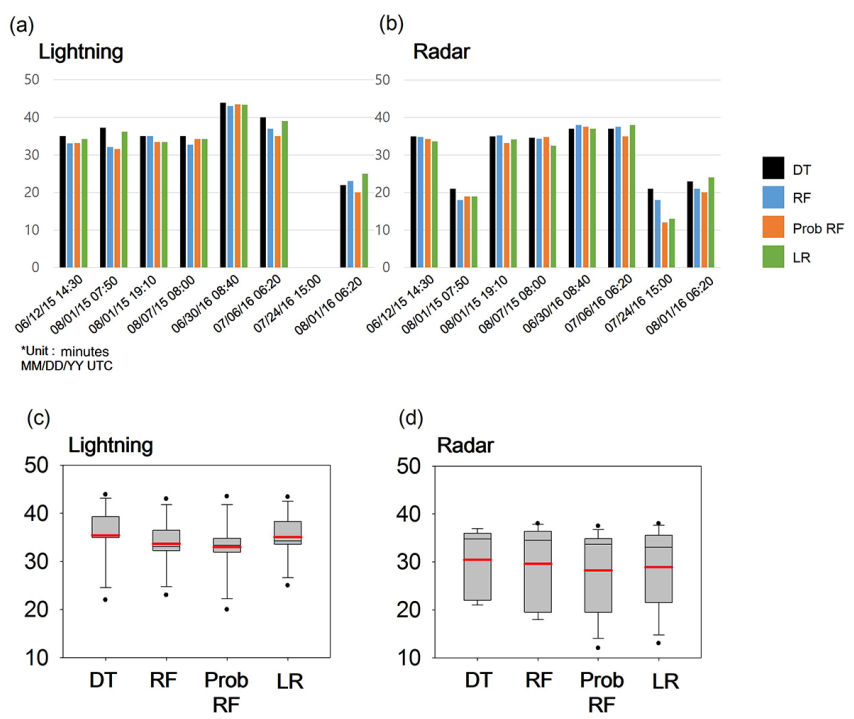

Figure 8. Averaged lead time based on lightning and radar CAPPI data for the deterministic DT and RF, probabilistic RF, and LR models. Box plot of lead time based on lightning and radar CAPPI data for the (c) lead time based on lightning data and (d) lead time based on radar CAPPI data. While red lines represent in the boxes mean value, grey lines represent median value.

even at the same time as $\mathrm{CI}$ occurred. The CI objects located around the west coast had a relatively high temperature at $11.2 \mu \mathrm{m}$. It is reported that warm-type heavy rainfall, lower storm height, with lower ice content have often developed over the ocean in eastern Asia (Sohn et al., 2013; Song and Sohn, 2015). Considering the temperature range of the CI objects, they appeared to be warm-type heavy rainfall clouds. As all four models are empirical, the missed CI cases imply that the training data did not contain such warm-type CI clouds. Fig. 12 shows CI events on 24 July 2016 at 14:50 (UTC) generated by four models. No lightning data were available in this case. CI objects were detected around latitude $38^{\circ} \mathrm{N}$ and longitude $128^{\circ} \mathrm{E}$ by all models except for the probabilistic RF model. Since CI objects in this case rapidly grew, it made lead time short and early detection of CI difficult. While FAR was almost zero, the averaged lead time was less than 20 min (Figs. 7 and 8).

The two validation data sets, i.e. the weather radar and lightning observations, influenced the assessment of model performance. Since the weather radar sites are located inland, convective clouds over the ocean were out of the detection radius and therefore less likely to be detected. Meanwhile, lightning observations can even detect CI objects over the distant sea, but it is hard to identify the exact location of lightning in clustered clouds. These limitations in each verification data set provide uncertainty in estimating the actual forecast skill of the CI detection models. Furthermore, since there were some heavy rainfall clouds without lightning ob- 
(a)

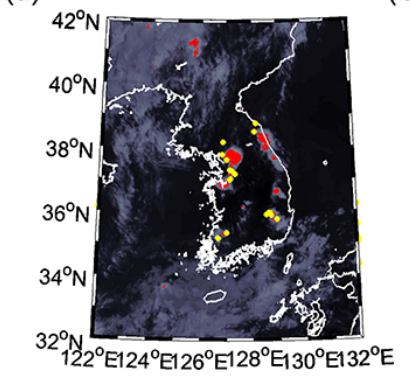

(c)

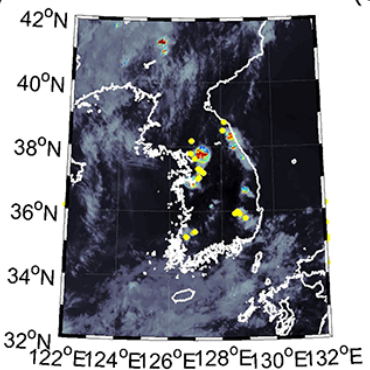

(b)

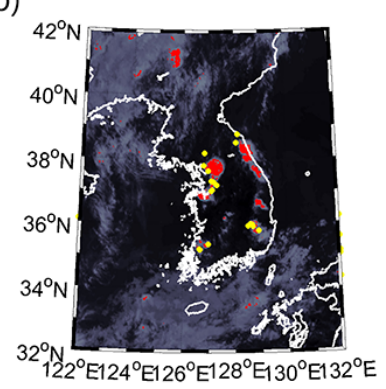

(d)

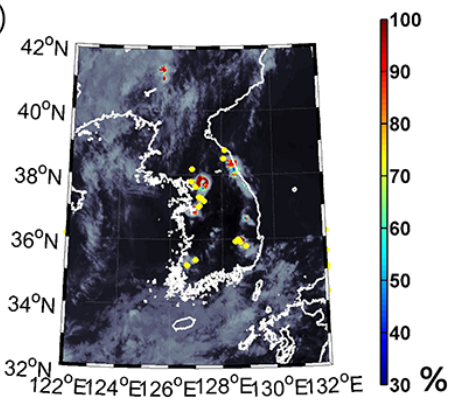

(e)

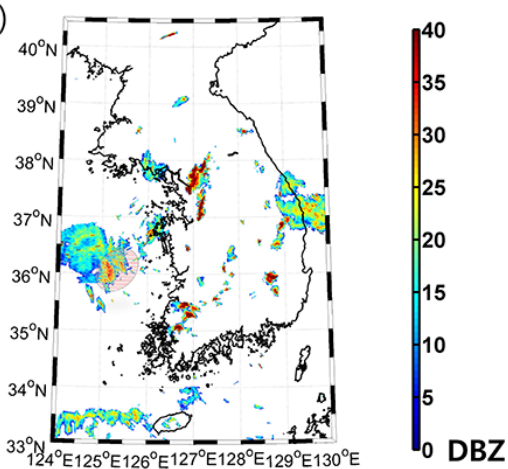

Figure 9. Deterministic CI detection map derived by DT, RF, probabilistic RF, and LR on 7 August 2015 at 07:30 (UTC): (a) DT, (b) RF, (c) Prob RF, and (d) LR 30 min before CI occurrence. Panel (e) is the $1.5 \mathrm{~km}$ radar CAPPI image at 08:00 (UTC). While predicted CI is in red, the locations of lightning occurrences at 08:00 (UTC) are presented in yellow dots. The radar echoes above $35 \mathrm{dBZ}$ beyond the effective radius of radar are shaded with red hatching.

(a)

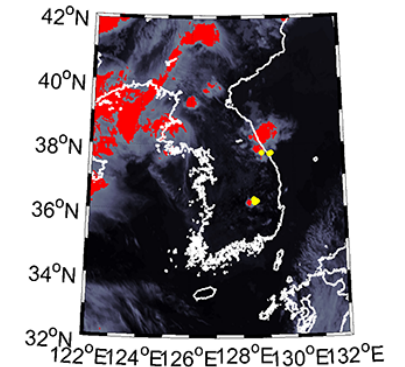

(c)

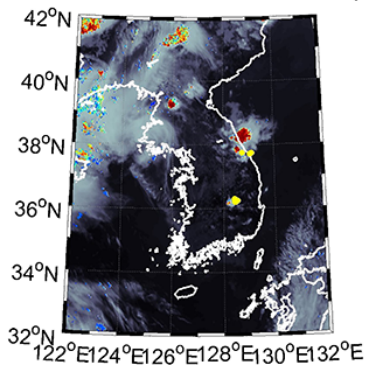

(b)

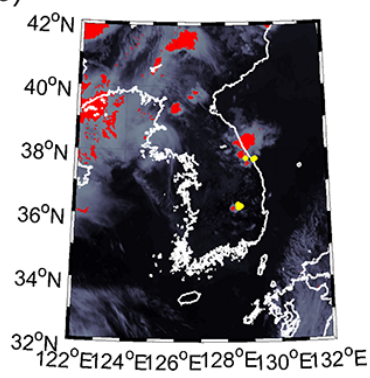

(d)

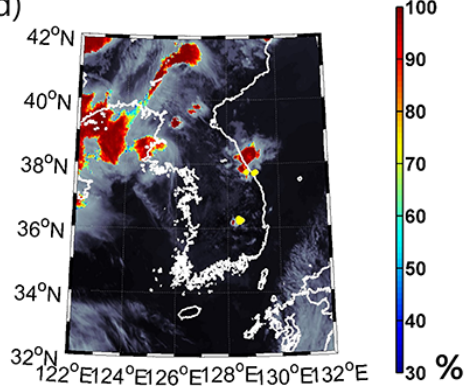

(e)

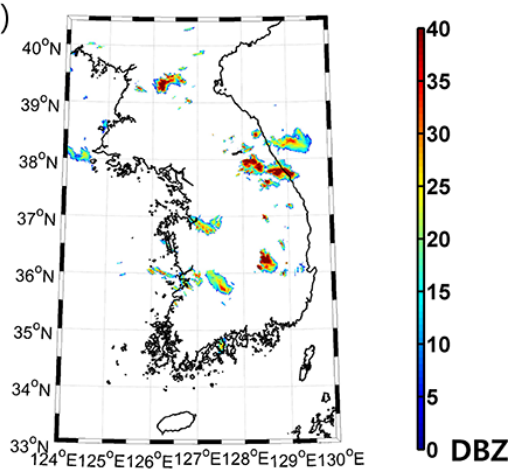

Figure 10. Deterministic CI detection map derived by DT, RF, probabilistic RF, and LR on 30 June 2016 at 08:00 (UTC): (a) DT, (b) RF, (c) probabilistic RF, and (d) LR 40 min before CI occurrence. Panel (e) is the $1.5 \mathrm{~km}$ radar CAPPI image at 08:40 (UTC). While predicted $\mathrm{CI}$ is in red, the locations of lightning occurrences at 08:00 (UTC) are presented in yellow dots.

servations, lighting data for CI reference was not reliable in the algorithm development stage.

Due to the similar number of hits from the four models, the lead time of all four models was around 32 to $40 \mathrm{~min}$. This indicates that CI over the Korean Peninsula can be forecasted using the Himawari-8 AHI images with a usable lead time of 30 to $40 \mathrm{~min}$, which is reasonably comparable to the lead time for CI detection ( 30-45 min) in the literature (Han 
(a)

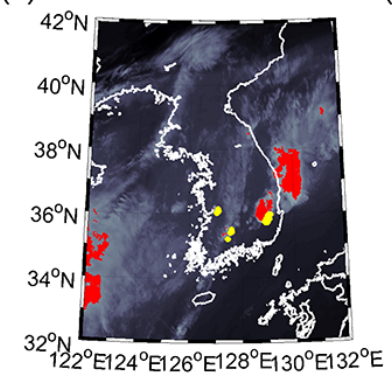

(c)

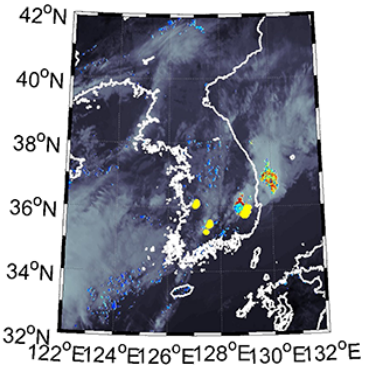

(b)

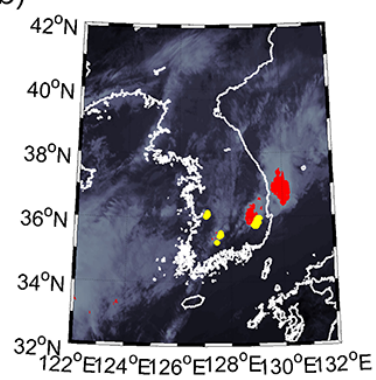

(d)

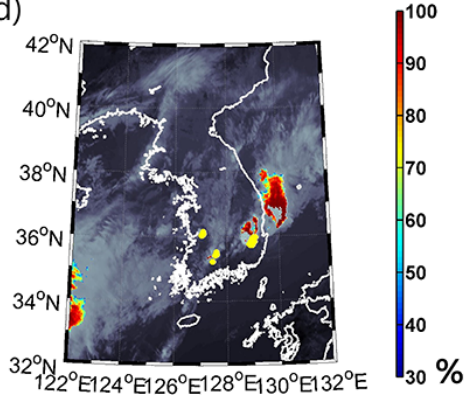

(e)

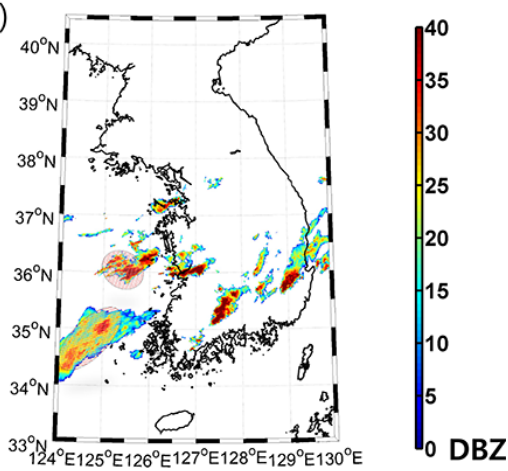

Figure 11. Deterministic CI detection map derived by DT, RF, probabilistic RF, and LR on 6 July 2016 at 05:30 (UTC): (a) DT, (b) RF, (c) probabilistic RF, and (d) LR 40 min before CI occurrence. Panel (e) is the $1.5 \mathrm{~km}$ radar CAPPI image at 06:10 (UTC). While predicted $\mathrm{CI}$ is in red, the locations of lightning occurrences at 06:10 (UTC) are presented in yellow dots. The radar echoes above $35 \mathrm{dBZ}$ beyond the effective radius of radar are shaded with red hatching.

(a)

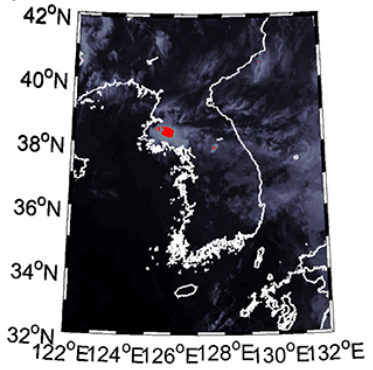

(c)

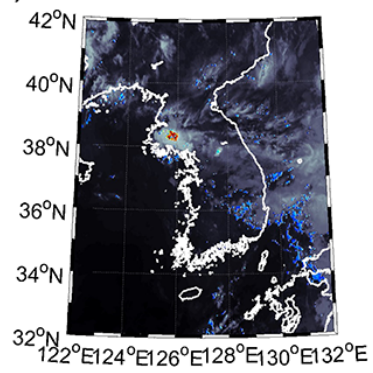

(b)

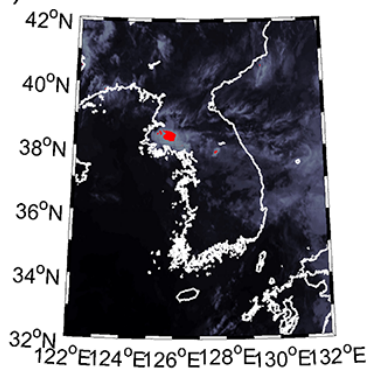

(d)

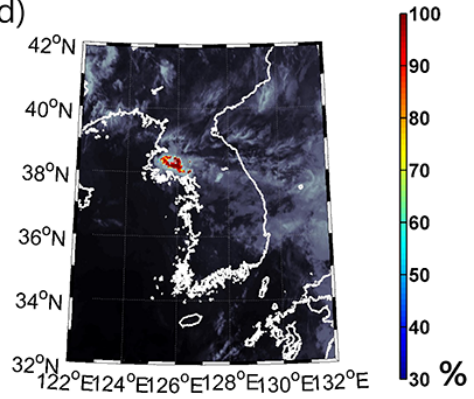

(e)

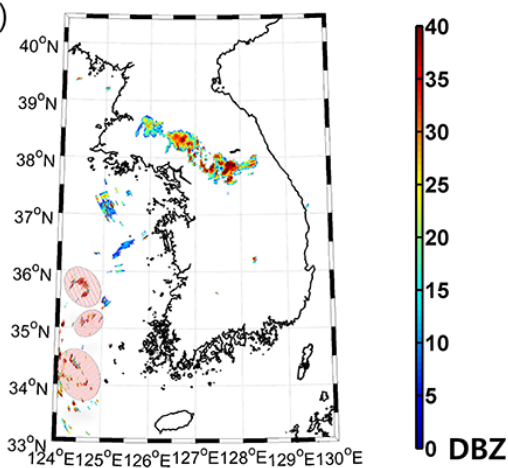

Figure 12. Deterministic CI detection map derived by DT, RF, probabilistic RF, and LR on 24 July 2016 at 14:50 (UTC): (a) DT, (b) RF, (c) probabilistic RF, and (d) LR 10 min before CI occurrence. Panel (e) is the 1.5 km radar CAPPI image at 15:00 (UTC). The radar echoes above $35 \mathrm{dBZ}$ beyond the effective radius of radar are shaded with red hatching.

et al., 2015; Mecikalski et al., 2015). AHI images were used to detect $\mathrm{CI}$ in this study $50 \mathrm{~min}$ before $\mathrm{CI}$ occurrence. If the AHI data collected a few hours before CI occurrence were used in the development of CI detection models, a longer lead time could possibly be achieved. Additionally, a rapid scan mode with 2 min temporal resolution may be used for rapidly growing clouds. 
A limitation of this research is that visible channels, which are critical in identifying cloud tops (Mecikalski et al., 2010), were not used. This was because many of the CI cases over the Korean Peninsula used in this study occurred at night time. The visible channels of Himawari-8 AHI have spatial resolutions of $0.5-1 \mathrm{~km}$ which can be used to improve the performance of $\mathrm{CI}$ detection models. The use of training samples and validation cases only from summer is another limitation. As the development of convective systems have a clear seasonality (Mecikalski et al., 2010), training samples and validation cases over different seasons should be incorporated to develop robust CI detection models.

\section{Conclusions}

CI detection models for Himawari-8 AHI data over the Korean Peninsula in eastern Asia were developed based on DT, RF, and LR. An accuracy assessment of the developed models was conducted using weather radar and lightning observations. The interest field of $11.2 \mu \mathrm{m} T_{\mathrm{b}}$, representing cloudtop temperature, was identified as the most contributing variable in the deterministic models and the probabilistic RF model. In the LR model, the trispectral difference, i.e. (8.6$11.2 \mu \mathrm{m})-(11.2-12.4 \mu \mathrm{m})$, was identified as the most important one. The developed CI detection models showed varied performance in terms of POD, FAR, OA, and CSI through CI cases and validation data sets. Nevertheless, the DT model produced generally higher POD than the other models, while the RF model showed higher OA and CSI, and lower FAR. The averaged lead time of the CI detection models was calculated between 20 and $40 \mathrm{~min}$, which means that a $30 \mathrm{~min}$ forecast of CI over the Korean Peninsula during summer is possible when using Himawari-8 AHI data.

The overlying method could produce a potential error when calculating the time trend interest fields that represent the vertical growth of convective clouds. AMV might mitigate the error and enhance the availability of time trend variables. Future research includes (1) improving CI detection algorithms using visible reflectance with $0.5 \mathrm{~km}$ resolution, (2) increasing training samples and validation cases to reflect diverse convective environments with different seasons, and (3) expanding the period of the Himawari- 8 AHI data $2 \mathrm{~h}$ before CI occurrence.

Data availability. Himawari data used in this study were provided by the Electronics and Telecommunications Research Institute (ETRI), Korea. The Korea Meteorological Administration (KMA) provides lightning and weather radar data. Additional registration is needed to access data (https://data.kma.go.kr/cmmn/main.do).

Competing interests. The authors declare that they have no conflict of interest.
Acknowledgements. This work was supported by the Development of Geostationary Meteorological Satellite Ground Segment (NMSC-2014-01) programme, funded by the National Meteorological Satellite Centre (NMSC) of the Korea Meteorological Administration (KMA).

Edited by: M. Portabella

Reviewed by: R. Clay and one anonymous referee

\section{References}

Amorati, R., Alberoni, P. P., Levizzani, V., and Nanni, S.: IR-based satellite and radar rainfall estimates of convective storms over northern Italy, Meteorol. Appl., 7, 1-18, doi:10.1017/S1350482700001328, 2000.

Banacos, P. C. and Schultz, D. M.: The Use of Moisture Flux Convergence in Forecasting Convective Initiation: Historical and Operational Perspectives, Weather Forecast., 20, 351-366, doi:10.1175/WAF858.1, 2005.

Bessho, K., Date, K., Hayashi, M., Ikeda, A., Imai, T., Inoue, H., Kumagai, Y., Miyakawa, T., Murata, H., Ohno, T., Okuyama, A., Oyama, R., Sasaki, Y., Shimazu, Y., Shimoji, K., Sumida, Y., Suzuki, M., Taniguchi, H., Tsuchiyama, H., Uesawa, D., Yokota, H., and Yoshida, R.: An Introduction to Himawari-8/9; Japan's New-Generation Geostationary Meteorological Satellites, J. Meteorol. Soc. Jpn., 94, 151-183, doi:10.2151/jmsj.2016-009, 2016.

Breiman, L.: Random Forests, Machine Learning, 45, 5-32, doi:10.1023/a:1010933404324, 2001.

Craven, J. P., Jewell, R. E., and Brooks, H. E.: Comparison between Observed Convective Cloud-Base Heights and Lifting Condensation Level for Two Different Lifted Parcels, Weather Forecast., 17, 885-890, doi:10.1175/15200434(2002)017<0885:CBOCCB>2.0.CO;2, 2002.

Guo, Z. and Du, S.: Mining parameter information for building extraction and change detection with very high resolution imagery and GIS data, GIS. Remote Sens., 54, 38-63, 2017.

Haile, A. T., Rientjes, T., Gieske, A., and Gebremichael, M.: Multispectral remote sensing for rainfall detection and estimation at the source of the Blue Nile River, Int. J. Appl. Earth Obs. Geoinf., S76-S82, 2010.

Han, H., Lee, S., Im, J., Kim, M., Lee, M. I., Ahn, M. H., and Chung, S. R.: Detection of convective initiation using Meteorological Imager onboard Communication, Ocean, and Meteorological satellite based on machine learning approaches, Remote Sens., 7, 9184-9204, 2015.

Hane, C. E., Rabin, R. M., Crawford, T. M., Bluestein, H. B., and Baldwin, M. E.: A Case Study of Severe Storm Development along a Dryline within a Synoptically Active Environment, Part II: Multiple Boundaries and Convective Initiation, Mon. Weather Rev., 130, 900-920, doi:10.1175/15200493(2002)130<0900:ACSOSS>2.0.CO;2, 2002.

Hosmer, D. W. and Lemeshow, S.: Applied Logistic Regressio, John Wiley and Sons, Inc., New York, 528 pp., 2000.

Houze, R. A.: Mesoscale convective systems, Rev. Geophys., 42, RG4003, 10.1029/2004RG000150, 2004.

Im, J., Jensen, J. R., and Tullis, J. A.: Object-based change detection using correlation image analysis and image segmentation, Int. J. 
Remote Sens., 29, 399-423, doi:10.1080/01431160601075582, 2008.

Im, J., Jensen, J., Jensen, R., Gladden, J., Waugh, J., and Serrato, M.: Vegetation cover analysis of hazardous waste sites in utah and arizona using hyperspectral remote sensing, Remote Sens., 4, 327-353, 2012.

Jensen, J. R. and Im, J.: Remote Sensing Change Detection in Urban Environments, in: Geo-Spatial Technologies in Urban Environments: Policy, Practice, and Pixels, edited by: Jensen, R. R., Gatrell, J. D., and McLean, D., Springer Berlin Heidelberg, Berlin, Heidelberg, 7-31, 2007.

Jewett, C. P. and Mecikalski, J. R.: Adjusting thresholds of satellitebased convective initiation interest fields based on the cloud environment, J. Geophys. Res-Atmos., 118, 12649-612660, doi:10.1002/2013JD019700, 2013.

Jorgensen, D. P. and LeMone, M. A.: Vertical Velocity Characteristics of Oceanic Convection, J. Atmos. Sci., 46, 621-640, doi:10.1175/1520-0469(1989)046<0621:VVCOOC >2.0.CO;2, 1989.

Kar, S. K. and Ha, K.-J.: Characteristic Differences of Rainfall and Cloud-to-Ground Lightning Activity over South Korea during the Summer Monsoon Season, Mon. Weather Rev., 131, 2312-2323, doi:10.1175/15200493(2003)131<2312:CDORAC>2.0.CO;2, 2003.

Kim, D. H. and Ahn, M. H.: Introduction of the in-orbit test and its performance for the first meteorological imager of the Communication, Ocean, and Meteorological Satellite, Atmos. Meas. Tech., 7, 2471-2485, 10.5194/amt-7-2471-2014, 2014.

Kim, H. W. and Lee, D. K.: An Observational Study of Mesoscale Convective Systems with Heavy Rainfall over the Korean Peninsula, Weather Forecast., 21, 125-148, doi:10.1175/WAF912.1, 2006.

Kim, M., Im, J., Han, H., Kim, J., Lee, S., Shin, M., and Kim, H.-C.: Landfast sea ice monitoring using multisensor fusion in the Antarctic, GIS. Remote Sens., 52, 239-256, doi:10.1080/15481603.2015.1026050, 2015.

Kim, Y. H., Im, J., Ha, H. K., Choi, J.-K., and Ha, S.: Machine learning approaches to coastal water quality monitoring using GOCI satellite data, GIS. Remote Sens., 51, 158-174, doi:10.1080/15481603.2014.900983, 2014.

Lawrence, R. L. and Wright, A.: Rule-based classification systems using classification and regression tree (CART) analysis, Photogramm. Eng. Rem. S., 67, 1137-1142, 2001.

Li, M., Im, J., and Beier, C.: Machine learning approaches for forest classification and change analysis using multi-temporal Landsat TM images over Huntington Wildlife Forest, GIS. Remote Sens., 50, 361-384, doi:10.1080/15481603.2013.819161, 2013.

Li, M., Im, J., Quackenbush, L. J., and Liu, T.: Forest Biomass and Carbon Stock Quantification Using Airborne LiDAR Data: A Case Study Over Huntington Wildlife Forest in the Adirondack Park, IEEE J. Sel. Top. Appl. Earth Obser. Remote Sens., 7, 3143-3156, doi:10.1109/JSTARS.2014.2304642, 2014.

Liu, T., Im, J., and Quackenbush, L. J.: A novel transferable individual tree crown delineation model based on Fishing Net Dragging and boundary classification, ISPRS J. Photogramme., 110, 34 47, doi:10.1016/j.isprsjprs.2015.10.002, 2015.

Lu, Z., Im, J., Quackenbush, L. J., and Yoo, S.: Remote Sensingbased House Value Estimation Using an Optimized Regional Re- gression Model, Photogramm. Eng. Remote Sens., 79, 809-820, doi:10.14358/PERS.79.9.809, 2013.

Lu, Z., Im, J., Rhee, J., and Hodgson, M.: Building type classification using spatial and landscape attributes derived from LiDAR remote sensing data, Landscape, Urban Plan., 130, 134 148, doi:10.1016/j.landurbplan.2014.07.005, 2014.

Mecikalski, J. R. and Bedka, K. M.: Forecasting Convective Initiation by Monitoring the Evolution of Moving Cumulus in Daytime GOES Imagery, Mon. Weather Rev., 134, 49-78, doi:10.1175/MWR3062.1, 2006.

Mecikalski, J. R., Bedka, K. M., Paech, S. J., and Litten, L. A.: A Statistical Evaluation of GOES Cloud-Top Properties for Nowcasting Convective Initiation, Mon. Weather Rev., 136, 48994914, doi:10.1175/2008MWR2352.1, 2008.

Mecikalski, J. R., MacKenzie, W. M., Koenig, M., and Muller, S.: Cloud-Top Properties of Growing Cumulus prior to Convective Initiation as Measured by Meteosat Second Generation. Part I: Infrared Fields, J. Appl. Meteorol. Climatol., 49, 521-534, doi:10.1175/2009JAMC2344.1, 2009.

Mecikalski, J. R., MacKenzie, W. M., König, M., and Muller, S.: Cloud-Top Properties of Growing Cumulus prior to Convective Initiation as Measured by Meteosat Second Generation. Part II: Use of Visible Reflectance, J. Appl. Meteorol. Climatol., 49, 2544-2558, doi:10.1175/2010JAMC2480.1, 2010.

Mecikalski, J. R., Williams, J. K., Jewett, C. P., Ahijevych, D., LeRoy, A., and Walker, J. R.: Probabilistic 0-1-h Convective Initiation Nowcasts that Combine Geostationary Satellite Observations and Numerical Weather Prediction Model Data, J. Appl. Meteorol. Climatol., 54, 1039-1059, doi:10.1175/JAMC-D-140129.1, 2015.

Merk, D. and Zinner, T.: Detection of convective initiation using Meteosat SEVIRI: implementation in and verification with the tracking and nowcasting algorithm Cb-TRAM, Atmos. Meas. Tech., 6, 1903-1918, 10.5194/amt-6-1903-2013, 2013.

Miyamoto, Y., Kajikawa, Y., Yoshida, R., Yamaura, T., Yashiro, H., and Tomita, H.: Deep moist atmospheric convection in a subkilometer global simulation, Geophys. Res. Lett., 40, 4922-4926, doi:10.1002/grl.50944, 2013.

Morel, C. and Senesi, S.: A climatology of mesoscale convective systems over Europe using satellite infrared imagery. I: Methodology, Q. J. Roy. Meteorol. Soc., 128, 1953-1971, doi:10.1256/003590002320603485, 2002.

Mueller, C., Saxen, T., Roberts, R., Wilson, J., Betancourt, T., Dettling, S., Oien, N., and Yee, J.: NCAR Auto-Nowcast System, Weather Forecast., 18, 545-561, doi:10.1175/15200434(2003)018<0545:NAS>2.0.CO;2, 2003.

Nyarko, B., Diekkruger, B., van de Giesen, N., and Vlek, P.: Floodplain wetland mapping in the White Volta River Basin of Ghana, GIS. Remote Sens. 52, 374-395, 2015.

Park, S., Im, J., Jang, E., and Rhee, J.: Drought assessment and monitoring through blending of multi-sensor indices using machine learning approaches for different climate regions, Agr. Forest Meteorol., 216, 157-169, doi:10.1016/j.agrformet.2015.10.011, 2016.

Quinlan, J. R.: Data mining tools See5 and C4.5, version 2.10, available at: https://www.rulequest.com/see5-info.html (last access: 10 February 2016), 2015.

Rhee, J., Im, J., Carbone, G. J., and Jensen, J. R.: Delineation of climate regions using in-situ and remotely-sensed data 
for the Carolinas, Remote Sens. Environ., 112, 3099-3111, doi:10.1016/j.rse.2008.03.001, 2008.

Rhee, J., Park, S., and Lu, Z.: Relationship between land cover patterns and surface temperature in urban areas, GIS. Remote Sens., 51, 521-536, doi:10.1080/15481603.2014.964455, 2014.

Roberts, N. M. and Lean, H. W.: Scale-Selective Verification of Rainfall Accumulations from High-Resolution Forecasts of Convective Events, Mon. Weather Rev., 136, 78-97, doi:10.1175/2007MWR2123.1, 2008.

Roberts, R. D. and Rutledge, S.: Nowcasting storm initiation and growth using GOES- 8 and WSR-88D data, Weather Forecast., 18, 562-584, 2003.

Rosenfeld, D., Woodley, W. L., Lerner, A., Kelman, G., and Lindsey, D. T.: Satellite detection of severe convective storms by their retrieved vertical profiles of cloud particle effective radius and thermodynamic phase, J. Geophys. Res-Atmos., 113, D04208, doi:10.1029/2007JD008600, 2008.

Schmit, T. J., Gunshor, M. M., Menzel, W. P., and Gurka, J. J.: Introducing the next-generation Advanced Baseline Imager on GOES-R, B. Am. Meteorol. Soc. 86, 1079-1096, 2005.

Sieglaff, J. M., Cronce, L. M., Feltz, W. F., Bedka, K. M., Pavolonis, M. J., and Heidinger, A. K.: Nowcasting Convective Storm Initiation Using Satellite-Based Box-Averaged Cloud-Top Cooling and Cloud-Type Trends, J. Appl. Meteorol. Climatol., 50, 110126, doi:10.1175/2010JAMC2496.1, 2011.

Siewert, C. W., Koenig, M., and Mecikalski, J. R.: Application of Meteosat second generation data towards improving the nowcasting of convective initiation, Meteorol. Appl., 17, 442-451, doi:10.1002/met.176, 2010.

Sobajima, A.: Rapidly Development Cumulus Areas Derivation Algorithm. Japan Meteorological Agency Algorithm Theoretical Basis Document, Meteorological Satellite Center, Tokyo, Japan, 2012.

Sohn, B. J., Ryu, G. H., Song, H. J., and Ou, M. L.: Characteristic features of warm-type rain producing heavy rainfall over the Korean Peninsula inferred from TRMM measurements, Mon. Weather Rev., 141, 3873-38881, 2013.

Song, H. J. and Sohn, B. J.: Two heavy rainfall types over the Korean peninsula in the humid East Asian summer environment: A satellite observation study, Mon. Weather Rev., 143, 363-382, 2015.

Torbick, N. and Corbiere, M.: Mapping urban sprawl and impervious surfaces in the northeast United States for the past four decades, GIS. Remote Sens., 52, 746-764, doi:10.1080/15481603.2015.1076561, 2015.
Trier, S. B., Chen, F., and Manning, K. W.: A Study of Convection Initiation in a Mesoscale Model Using High-Resolution Land Surface Initial Conditions, Mon. Weather Rev., 132, 2954-2976, doi:10.1175/MWR2839.1, 2004.

Tu, J. V.: Advantages and disadvantages of using artificial neural networks versus logistic regression for predicting medical outcomes, J. Clin. Epidemiol., 49, 1225-1231, doi:10.1016/S08954356(96)00002-9, 1996.

Walker, J. R., MacKenzie, W. M., Mecikalski, J. R., and Jewett, C. P.: An Enhanced Geostationary Satellite-Based Convective Initiation Algorithm for 0-2-h Nowcasting with Object Tracking, J. Appl. Meteorol. Climatol., 51, 1931-1949, doi:10.1175/JAMCD-11-0246.1, 2012.

Walker, J. R. and Mecikalski, J. R.: Algorithm theoretical basis document (ATBD) for convective initiation. NOAA NESDIS Center for Satellite Applications and Research, available at: http://www.nsstc.uah.edu/SATCAST/docs/ GOES-RAWGATBDAviationConvectiveInitiationv2.0.pdf (last access: 10 February 2016), 2011.

Wang, C.-C., Chen, G. T.-J., and Carbone, R. E.: A Climatology of Warm-Season Cloud Patterns over East Asia Based on GMS Infrared Brightness Temperature Observations, Mon. Weather Rev., 132, 1606-1629, doi:10.1175/15200493(2004)132<1606:ACOWCP>2.0.CO;2, 2004.

Weckwerth, T. M. and Parsons, D. B.: A Review of Convection Initiation and Motivation for IHOP_2002, Mon. Weather Rev., 134, 5-22, doi:10.1175/MWR3067.1, 2006.

Vondou, D. A., Nzeukou, A., and Kamga, F. M.: Diurnal cycle of convective activity over the West of Central Africa based on meteosat images, Int. J. Appl. Earth Obs. Geoinf., S58-S62, 2010.

Yoo, S., Im, J., and Wagner, J. E.: Variable selection for hedonic model using machine learning approaches: A case study in Onondaga County, NY, Landscape. Urban Plan., 107, 293-306, doi:10.1016/j.landurbplan.2012.06.009, 2012.

Zinner, T., Mannstein, H., and Tafferner, A.: Cb-TRAM: Tracking and monitoring severe convection from onset over rapid development to mature phase using multi-channel Meteosat8 SEVIRI data, Meteorol. Atmos. Phys. 101, 191-210, doi:10.1007/s00703-008-0290-y, 2008.

Zuidema, P.: Convective Clouds over the Bay of Bengal, Mon. Weather Rev., 131, 780-798, doi:10.1175/15200493(2003)131<0780:CCOTBO>2.0.CO;2, 2003. 